\title{
Attitudes towards Business Ethics Held by Accountancy and Finance Students in the University of Botswana
}

\author{
Percy M. D. Phatshwane ${ }^{1}$, Mogotsinyana Mapharing ${ }^{1} \&$ Elang J. Basuhi ${ }^{1}$ \\ ${ }^{1}$ Department of Accounting and Finance, University of Botswana, Botswana \\ Correspondence: Percy M. D. Phatshwane, University of Botswana, Department of Accounting and Finance, \\ Faculty of Business, P/ Bag UB 00701, Gaborone, Botswana. E-mail: phatshwane@mopipi.ub.bw
}

Received: August 30, 2013

Accepted: December 4, 2013

Online Published: January 20, 2014

doi:10.5539/ijbm.v9n2p17

URL: http://dx.doi.org/10.5539/ijbm.v9n2p17

\begin{abstract}
The current study is borne out of an interest on the ethical views of accounting majors, as well as evaluating their perceptions on certain ethical behaviour. The study is timely since it was undertaken at a time when the University of Botswana's Accountancy degree curriculum had been reviewed and a course in ethics in accounting was introduced. The Attitudes Towards Business Ethics Questionnaire (ATBEQ) was distributed to students who had completed the ethics and auditing courses. Willing respondents were invited for focus group discussions in order to gain additional insight on respondents' views and ethical perceptions.

The results of the current study were compared to the results of similar studies carried out in South Africa and Turkey. The findings of the study revealed that the mean average of the Botswana study was approximated by the South African results for some variables, and that there were isolated similarities with the Turkey findings. The results also indicated that an overwhelming number of respondents belief that business ethics can be taught, an encouraging result for a course in its infancy. It was however the qualitative results which, though limited, provided insight into the perceptions and thoughts of respondents on various aspects of ethical behaviour. Subsequently the study concluded that more concerted qualitative studies could provide further insight on the phenomenon and augment what has been learnt from the many quantitative studies.
\end{abstract}

Keywords: attitudes towards business ethics, students, triangulated study, Botswana

\section{Introduction}

The growing demise of organisations in global markets has enthused both business practitioners and researchers to locate factors influencing business ethical attitudes. This venture has turned out to be somewhat multi-faceted, complex and embedded in a range of societal, religious, philosophical, economical and institutional factors. For example, Moore \& Radloff (1996); Ahmed et al., (2003); Scholtens \& Dam (2007) recognize the role that culture plays in determining the behaviour of individuals when engaging in the affairs of corporations. Other studies have explored the effects of various religious and philosophical teachings on work and business ethics (Rokham, 2010; Rice, 1999; Emerson \& McKinney, 2010; Lim \& Lay, 2003). More recently studies that investigate the ethical behaviour patterns have tended to do so along national considerations, an affirmation of the significance of cultural patterns and 'coding' on ethical conduct (see for example Prebel and Reichel, 1988; Sims \& Gegez, 2004; Phau \& Kea, 2006 ). Many of these studies have utilized the Attitudes towards Business Ethics Questionnaire (ATBEQ) which was constructed by Neuman and Reichel (1987).

In the context of Sub-Saharan Africa, researchers have endeavoured to analyse various issues that are significant in understanding and addressing challenges in business ethical practices. Malanzi (1997) maps some of the societal, political and educational issues that have led to the significant drive towards understanding ethical practices within business institutions. However, Malanzi (ibid) goes on to lament that little is known on the phenomenon since there are limited studies that have been undertaken in the continent. Rossouw (1997) and Gichure (2006) also examined the extent to which academic institutions engage in the teaching of business ethics, and both conclude that there is dire need for the promotion of business ethics within academic institutions. Studies have also has been undertaken in South Africa to examine business ethics and behaviour patterns of business students and professional accountants (Moore \& Radloff, 1996; Maree \& Radloof 2007; Fatoki \& Marembo, 2012). The Moore and Radloff study is of particular interest to the current paper since it not only used the ATBEQ, but also undertook the study in a University. 
The current study is motivated in part by a desire to contribute towards a growing interest on students' attitudes towards business ethics in different geographic and cultural contexts. The timing of this paper is particularly significant since the University of Botswana has recently introduced a course in business and accounting ethics. The study introduces data triangulation alongside the use of the ATBEQ, a methodology that will enrich the study by allowing respondents to offer further insight on their experiences and perceptions having undertaken an ethics course. The paper begins by reviewing studies that have examined business ethics, especially those conducted in Sub-Saharan Africa.

\section{Literature Review}

\subsection{African Cultural Perspectives and Their Impact on Business Practices}

Hofstede's (1984) pioneering work has provided the most contentious reference point to researchers on cultural perspectives. Although appealing because of its global coverage, it has been criticised for its broad perspective of culture and its failure to explore the origins of cultural distinctiveness and their effect on managerial control and business enterprise (McSweeney, 2002). The work of Hofstede will therefore be used here to examine some of the cultural features identified within the dimensions (individualism/collectivism, uncertainty avoidance, power distance and masculinity/femininity). Not all the dimensions will be relevant to management and organisational control aspects in the African context, therefore some will be emphasised more than others in the current article.

Hofstede's initial cultural measures contained four dimensions that are said to shape the behavioural patterns of individual. The first dimension, the uncertainty avoidance index, measures the extent to which a society accepts or avoids the unknown. A high uncertainty avoidance is an indication that a society values structure and order, and that rules are accepted as a way of mitigating uncertainty. A low uncertainty avoidance indicates that the culture values people who are risk taking and depicts limited structure and rules in operations. Power distance, the second dimension, is said to be the degree to which less powerful members accept that power is distributed unequally. High power distance indicates that authoritative figures are expected to lead. A low power distance society expects power to be shared more equally. The third, individuality versus collectivism pertains to how personal goals and needs are espoused over the goals and needs of the group. In individualistic societies individuals tend to lose ties with the group such that the individual becomes most important, whilst collective societies value the group as the most important unit to serve. Finally, masculinity versus femininity measures whether society has different roles for men and women. In masculine countries women display masculine traits, but not as much as men. The dominant trait for the masculine personality would be assertiveness as compared to the feminine personality which should be more modest and caring.

Although Botswana is not specifically mentioned as a country included in the Hofstede study, West Africa, East Africa and South Africa were assessed and given specific measures in all four dimensions.

Within business ethics studies, the uncertainty avoidance index (UAI) and the individualism versus collectivism index have been determined to be the most influential. These indices are said to affect patterns of business practices and behavioural patterns therein (see for example Wennerekers et al., 2007). The results of the Hofstede study for these two indices in the nations and regions of interest to this study (East Africa, South Africa, Zambia and Turkey) are presented in the table below:

Table 1. Summary of individualism vs. collectivism and uncertainty avoidance index scores for East Africa, South Africa, Zambia and Turkey

\begin{tabular}{|c|c|c|c|c|c|}
\hline Index & & East Africa & South Africa & Zambia & Turkey \\
\hline $\begin{array}{l}\text { Individualism } \\
\text { collectivism }\end{array}$ & vs. & 27 (collectivism) & 65 (moderate individualism) & 35 (moderate collectivism) & 37 (moderate collectivism) \\
\hline $\begin{array}{l}\text { Uncertainty } \\
\text { avoidance index }\end{array}$ & & 52 (moderate) & 49 (moderate) & 50 (moderate) & 85 (strong) \\
\hline
\end{tabular}

On the uncertainty avoidance index (UAI) Hofstede's model classifies African society as having fairly strong uncertainty avoidance (average of 53), and being relatively high collectivism (see also Mbigi \& Maree, 1995: Deng, 1997; Mangaliso, 1997 for similar views). However, the individualism versus collectivism score for South Africa has been contested since its culture is multi-racial; informed by British, Dutch, Indian and Black native influence. Thomas and Bendixen (2000), who scored White managers as having a UAI score of 30.7 and 
their Black counterparts 76.4, appear to acknowledge these differences. In fact Kruger and Roodt (2003) contend that the findings of the Hofstede studies are unreliable and invalid in the South African context given the multiplicity of the country's cultures and the failure of the study to distinguish respondents by their cultural identity. In contrast, other Sub-Saharan African countries included in the Hofstede study as part of West or East Africa (Nigeria, Ghana, Sierra Leone, Kenya, Zaire, Zambia \& Zimbabwe) have maintained African customs, traits and practices.

\subsection{Previous ATBEQ University-Based Studies}

Following the initial study carried out by Prebel and Reichel (1988), researchers in different national contexts undertook studies that not only reported the findings using the ATBEQ in their county or region, but also sought comparisons between their findings and those made by other researchers. The explanation for differences in the results reported by the various studies was often explained or put down to cultural differences. Within these studies some researchers looked for differences in the results along gender lines. The results of this line of enquiry were mixed since males were determined to exhibit higher ethical values than their female counterparts by some studies (see Phau \& Kea, 2007; Peterson et al., 2010) while another study reported that there were no significant differences in the results between the sexes (Perryer \& Jordon, 2002). A summary of the more prominent studies is given in Table 2.

Table 2. Summary of prominent ATBEQ studies

\begin{tabular}{lll}
\hline Authors & Country / countries & $\begin{array}{l}\text { Dominant Theory/Factor used in } \\
\text { Comparison }\end{array}$ \\
\hline Prebel and Reichel (1988) & USA and Israel & No specific factor \\
Small (1992) & Australia & No specific factor \\
Moore and Radloff (1996) & South Africa & No specific factor \\
Sims and Gegez (2004) & Turkey & National culture \\
Phau and Kea (2007) & Australia, Singapore and Hong Kong & Cultural values, business ethics, \\
& & religion \\
Bageac, Furrer and Reynaud (2011) & France and Romania & Business Philosophies \\
Fatoki and Marembo (2012) & South Africa & National culture \\
\hline
\end{tabular}

\subsection{Teaching Business Ethics and Religious Beliefs}

In addition to cultural factors, teaching of business ethics in colleges and religious beliefs have been investigated by researches as they are been deemed to be influential values in the ethical behaviour. Teaching ethics in business schools and colleges is a relatively new development in the accountancy discipline. In the same way that legal, medical and other professionals are required to receive some form of ethics education as part of their formal training in an attempt to develop high levels of ethical awareness and conduct, many accounting researchers and practitioners have shown their support for the inclusion of ethics in the accounting curriculum (see for example Bean \& Bernardi, 2007; Macfarlane, 1995 \& 1998; Weber, 1997; Sims, 2002). The position of these studies is that teaching ethics and other forms of accounting professional conduct would have a positive impact on the ethical behaviour and perception of accountants. This seemingly optimistic postulate has, however, come under scrutiny. While Bernardi and Bean (2006) question whether business ethics can and should be taught, Gundersen et al. (2008) doubt that teaching business ethics enhances ethical behaviour. These studies, however, do not advance reasons for their scepticism.

Another variable that has been studied or associated with business ethics is religious beliefs. Given the general course and content of religious teaching one would expect a positive relationship between the 'religiousness' of an individual and the ethical values that they espouse (Turner, 1997; Weaver \& Agle, 2002; Kim et al., 2009). The guidance and moral content of religious teaching are expected to provide moral guidance to followers. A study by Emerson and McKinney (2010) found that there was strong evidence that individuals who professed to have high ethical beliefs were less accepting of questionable ethical behaviour.

Despite the overwhelming and robust literature pointing to an association between religious beliefs and business ethics, calls have been made for researchers to investigate the effect of the following on ethical behaviour: differences in levels of religious commitment, religious affiliation and an individual's life experience (Emerson \& Mckinney, 2010). 


\section{Research Methodology}

\subsection{Study Design}

From the onset the researchers intended going beyond the commonly used ATBEQ, and obtain qualitative data from respondents on their views of business ethics as informed by their personal experiences and the effect of formal University courses in shaping their views on the subject-matter. The decision to triangulate data was certainly supported by limitations encountered when comparing results of the current study with prior studies as raw data from these studies was not available.

The first phase of the enquiry involved the use of ATBEQ questionnaires in collecting data from students. Once these questionnaires had been collected and analysed, the results summarized, respondents were invited for focus group discussions. This formed the qualitative part of the study. The main focus of the qualitative study was to gain further insight on some of the results obtained from the questionnaires enquiry. A discussion of the quantitative and qualitative phases of the study follows.

\subsection{The Quantitative Data}

The research instrument used to collect data for this study was a self-administered questionnaire which adopted questions on the ATBEQ which has been used in similar studies and was constructed by Neumann and Reichel (1987), cited in Preble and Reichel (1988). Although this instrument was initially employed in the study of ethical practices among managers, the suitability of its use in the study of undergraduate students has been asserted by several studies (see for example Ahmed et al., 2003; Small, 1992, Preble \& Reichel, 1988).

The standard 30-question ATBEQ was piloted with 9 participants to test understanding and appropriateness of the questions. The feedback revealed that some of the questions were either difficult to understand or could not be comprehended properly. This was put down to limitations in understanding the business language and the cultural context of some of the questions given students' limited exposure to the business environment. Subsequently 7 items from the original ATBEQ were not included in the questionnaire. Two additional questions which enquired on respondents perceptions on 'whether ethics can be taught, and should be taught at University' and 'whether a person's moral judgement is influenced by his or her religion' where adapted from an instrument used by Maree and Radloff (2007).

Broadly speaking, the questions in the ATBEQ instrument can be divided into two types of questions: those that relate to an individual's conceptualization or understanding of the business world and the way business ethics operates therein. Examples of such questions include 'business decisions involve a realistic economic attitude and not a moral philosophy', 'employee wages should be according to the laws of supply and demand' and 'the business world has its own rules'. The second type of questions related to a person's moral values and their value systems. Questions like these include 'I view sick days as vacation leave' and 'as a consumer when making a car insurance claim, I try to get as much as possible regardless of the extent of the damage'.

\subsection{Sampling}

The data for this study was collected using convenient sampling. Initially 240 questionnaires were distributed to nationals (Tswana) Accountancy and Finance students who had taken modules in two courses; Ethics in Accounting and Auditing. Although only nationals were asked to respond to the questionnaire, nationals who had stayed or studied outside the country for extended periods (more than 6 months) were excluded from the study since, according to Palumbo and Teich (2004), the validity of a study will be reduced if cultural influences that have been identified as being significant in affecting ethical behaviour are not given due consideration when selecting participants.

A total of 212 questionnaires were received, an $88 \%$ response rate. Ultimately 195 usable questionnaires were included in the study. This excluded 17 (less than $1 \%$ ) of the responses which were either not completed in a manner that would deem them usable, or had been submitted by non-locals. A total of 138 usable responses were from females, while the remaining 57 were from their male counterparts.

\subsection{Data Processing}

A database was created from the questionnaire responses using SPSS Statistics. Differential statistical tests were performed on the data to generate means and standard deviation values. The study also relied on secondary data for responses to the ATBEQ from Turkey (Sims \& Gezez, 2004) and South Africa (Moore \& Radloff, 1996) for comparison. Ideally, the use of statistical tools such as ANOVA or MANOVA tests would have been beneficial to the study. However, given that the data reported by the two studies was limited to mean values, standard deviation and sample size, this detailed statistical analysis was not possible. This limitation resulted in the study 
being restricted to the use of descriptive statistics as the actual results obtained from the pool of responses were not available. Subsequently ANOVA tests were only run for the primary data obtained from Botswana respondents.

\subsection{The Qualitative Data}

Students who responded to the questionnaire were invited to form small focus groups of not more than 5 individuals to make follow-up discussions on issues covered by the questionnaire. The individuals who had volunteered to participate in these focus groups were then interviewed. This method resulted in a relatively low response rate since only 4 groups immerged with a total of 17 respondents. Only a single group, Group Two, had male respondents as indicated on Table 3 below. The other three groups were exclusively female.

Table 3. Focus groups and their number of respondents

\begin{tabular}{ccc}
\hline Group & Number of respondents & Composition by gender \\
\hline One & 4 & All female \\
Two & 5 & Three females, two males \\
Three & 4 & All female \\
Four & 4 & All female \\
\hline
\end{tabular}

\section{Findings of the Study}

The usable questionnaire responses were analysed and descriptive statistics generated from SPSS for comparison. Each statement on the questionnaire was treated as a separate variable labelled ' $\mathrm{V}$ '. The results of the mean and standard deviation values for these variables are as below:

Table 4. Descriptive statistics results for ATBEQ for the Botswana study

\begin{tabular}{|c|c|c|c|}
\hline Question & Mean & $\begin{array}{l}\text { Standard } \\
\text { deviation }\end{array}$ & $n$ \\
\hline V1. A person who is doing well in business does not have to worry about money problems. & 2.04 & 1.12 & 195 \\
\hline $\begin{array}{l}\text { V2. Every business person acts according to moral principles, whether he/she is aware of it or } \\
\text { not. }\end{array}$ & 2.68 & 1.17 & 195 \\
\hline V3. Act according to the law, and you can't go wrong morally. & 2.68 & 1.20 & 193 \\
\hline V4. Business decisions involve a realistic economic attitude and not a moral philosophy. & 3.27 & 1.11 & 195 \\
\hline V5. Moral values are irrelevant to the business world. & 1.93 & 1.14 & 192 \\
\hline V6. The lack of public confidence in the ethics of business people is not justified. & 2.82 & 0.98 & 195 \\
\hline V7. The only moral of business is making money. & 2.33 & 1.23 & 195 \\
\hline V8. 'Business ethics' is a concept for public relations only. & 2.10 & 0.96 & 195 \\
\hline $\begin{array}{l}\text { V9. The business world today is not different from what it used to be in the past. Business Ethics } \\
\text { has not changed over the past few years. }\end{array}$ & 2.26 & 1.07 & 195 \\
\hline V10. Competitiveness and profitability are independent values (existing on their own). & 2.52 & 1.12 & 193 \\
\hline $\begin{array}{l}\text { V11. As a consumer when making a car insurance claim, I try to get as much as possible } \\
\text { regardless of the extent of the damage. }\end{array}$ & 3.11 & 1.19 & 195 \\
\hline $\begin{array}{l}\text { V12. While shopping at the supermarket it is appropriate to switch price tags if the opportunity } \\
\text { arises. }\end{array}$ & 1.88 & 1.18 & 195 \\
\hline V13. As an employee, I take office supplies home; it doesn’t hurt anyone. & 1.81 & 1.02 & 192 \\
\hline V14. I view sick days as vacation days that I deserve. & 2.29 & 1.23 & 195 \\
\hline V15. Employee wages should be determined according to the laws of supply and demand. & 2.77 & 1.26 & 195 \\
\hline $\begin{array}{l}\text { V16. For every decision in business the only question I ask is, 'Will it be profitable?'. If yes - I } \\
\text { will act according; if not, it is irrelevant and a waste of time. }\end{array}$ & 3.2 & 1.41 & 195 \\
\hline
\end{tabular}




\begin{tabular}{lcc}
\hline V17. In my grocery store every week I raise the price of a certain product and mark it 'on sale'. & 1.99 & 0.97 \\
There is nothing wrong with doing this. & 3.27 & 195 \\
V18. The business world has its own rules & 3.15 & 1.08 \\
V19. A good business person is a successful business person. & 3.08 & 1.34 \\
V20. True morality is first and foremost self-interest. & 2.37 & 1.20 \\
V21. Self-sacrifice is immoral. & 3.96 & 1.17 \\
V22. You can judge a person according to his work and his dedication. & 194 \\
V23. You should not consume more than you produce. & 3.90 & 1.12 \\
\hline
\end{tabular}

\subsection{Comparison by Gender}

The results revealed no discernible difference in the mean when comparing male and female respondents for most questions. However, there were some differences in means for V4, V7, V16 and V17 where males had a higher mean than their female counterparts. Interestingly most of these questions related to conceptual issues on business ethics and the business world (V4, V7 and V16). Only V17 addressed a moral value stance. Further tests using ANOVA t-test revealed that there were significant differences at the $95 \%$ level for all four values (V4, $\mathrm{V} 7, \mathrm{~V} 16$ and V17) in relation to gender.

Table 5. Results for test of significance

\begin{tabular}{cc}
\hline Value & At 95\% Confidence Interval \\
\hline V4 & 0,003 \\
V7 & 0.037 \\
V16 & 0.041 \\
V17 & 0.028 \\
\hline
\end{tabular}

Where $\mathrm{N}=$ male 57, Female 138 .

To support these findings, a comment by a female respondent in an all-female group prompted a discussion on ethical conduct along gender lines.

Respondent 1: We [female] are not as brave as men and are afraid of engaging in some of these [unethical] activities. Even here in school you find guys trying to cheat in tests. Most girls are afraid of even trying to do this.

Respondent 2: But you can't say that women don't do this. We have done case studies in class where women were unethical. Like Martha Stewart.

Respondent 3: Yes, but I think what she means is that most of the time it was guys.

Group 4 respondents.

\subsection{Perceptions on Teaching Ethics and the Effect of Religion on Moral Judgement}

Two additional questions which do not appear on the ATBEQ but were included in the Maree and Radloff (2007) study were intended on finding respondents' perceptions on whether ethics is an area that can and should be taught at university level. This question was of particular significance since the respondents were the first group of students that had taken a course in accounting ethics. The results of the two additional questions included in the study are presented in the table below:

Table 6. Responses on whether ethics can be taught and if religion influences a persons' moral judgement

\begin{tabular}{|c|c|c|c|c|c|c|}
\hline Question & Yes & Not Sure & No & Mean & $\begin{array}{l}\text { Standard } \\
\text { deviation }\end{array}$ & $n$ \\
\hline $\begin{array}{l}\text { V24 Do you believe that ethics can be taught and } \\
\text { should be taught at university? }\end{array}$ & $\begin{array}{l}148 \\
(76 \%)\end{array}$ & $\begin{array}{l}17 \\
(9 \%)\end{array}$ & $\begin{array}{l}30 \\
(15 \%)\end{array}$ & 1.41 & 0.72 & 192 \\
\hline $\begin{array}{l}\text { V25 Do you believe that a person's moral judgement } \\
\text { is influenced by his or her religious belief }\end{array}$ & $\begin{array}{l}166 \\
(85 \%)\end{array}$ & $\begin{array}{l}20 \\
(11 \%)\end{array}$ & $\begin{array}{l}9 \\
(4 \%)\end{array}$ & 1.23 & 0.56 & 191 \\
\hline
\end{tabular}


It is worth noting that the results of the current study revealed that $76 \%$ of the respondents believed that ethics can and should be taught at university. The study by Maree and Radloff (2007) reported an aggregate average of $87 \%$ (the question had been separated into two components; whether ethics can be taught and if it should be taught at university). Although the 'yes' response rate of $76 \%$ is lower than the $85 \%$ reported by the other study, it is encouraging that in its initiation year a good number of students felt that ethics should be taught.

On the question of whether a person's moral judgement is influenced by religion, $85 \%$ of the respondents gave an affirmative response compared to $60.6 \%$ of respondents in the Maree and Radloff (2007) study. The response to this question showed a marked difference in perception between the two studies. Age may certainly explain the disparity in perceptions since the South African based study already suggested that there was a significant relationship between age and some aspects of ethics (Maree \& Radloff, 2007, p. 9). Furthermore, most respondents in the Maree and Radloff study fell within the 31-45 years age group compared to current study where $92 \%$ of the respondents were in the 18-22 age group.

The likely impact of religion on morality and business ethics was one of the most discussed areas during group discussion. Respondents revealed that religion teaches us to do well, and most appeared to agree that the business arena was certainly one of those domains that would compel us to do well. However tensions between religion, doing good and business-motives were revealed by some respondents. The following reveals some of the concerns raised by respondents:

When I go to (a religious place) I know that I should behave in a certain way when (associating) with people. So this is how I should behave and be to other people. But have you ever heard a person at church say be like this also at work or people at work say remember what you were taught at church? The (link) is not always there. Group 3 respondent

The inference here appeared to be that we have a leader at work for guidance on behaviour patterns in the workplace, and a religious leader for everything else. When asked how they would resolve the issue if there were tensions between what they saw as 'work ethics' and 'religiously-informed ethics' three respondents suggest that it was better to do good and keep one's hands clean. Only one respondent argued that she felt that where 'bread and butter' issues are concerned it may not be so easy in practice.

\subsection{Comparisons to Previous Studies}

Perhaps because of its proximity to Botswana and some of its shared history, South Africa was the most appealing nation for making comparisons with the results of the current study. However mean values for Turkey were also used as a third-country comparator. A summary of the descriptive statistic results for all three countries are given in table 6 below.

Table 7. Descriptive statistics results for ATBEQ for the Botswana, South Africa and Turkey

\begin{tabular}{|c|c|c|c|c|c|c|}
\hline \multirow{2}{*}{ Question } & \multicolumn{2}{|c|}{ Botswana } & \multicolumn{2}{|c|}{ South Arica\# } & \multicolumn{2}{|c|}{ Turkey* } \\
\hline & Mean & sd & Mean & sd & Mean & $\mathrm{sd}$ \\
\hline $\begin{array}{l}\text { V1. A person who is doing well in business does not have to } \\
\text { worry about money problems. }\end{array}$ & 1.74 & 1.12 & 1.68 & 0.66 & 2.05 & 1.66 \\
\hline $\begin{array}{l}\text { V2. Every business person acts according to moral principles, } \\
\text { whether he/she is aware of it or not. }\end{array}$ & 2.68 & 1.17 & 2.97 & 1.21 & 2.82 & 1.19 \\
\hline V3. Act according to the law, and you can't go wrong morally. & 2.68 & 1.20 & 2.09 & 0.74 & 2.48 & 1.15 \\
\hline $\begin{array}{l}\text { V4. Business decisions involve a realistic economic attitude and } \\
\text { not a moral philosophy. }\end{array}$ & 3.27 & 1.11 & 3.09 & 1.14 & 2.65 & 1.10 \\
\hline V5. Moral values are irrelevant to the business world. & 1.93 & 1.14 & 1.76 & 0.63 & 2.12 & 1.12 \\
\hline $\begin{array}{l}\text { V6. The lack of public confidence in the ethics of business } \\
\text { people is not justified. }\end{array}$ & 2.82 & 0.98 & 2.73 & 0.98 & 2.97 & 1.06 \\
\hline V7. The only moral of business is making money. & 2.33 & 1.23 & 2.31 & 1.29 & 2.15 & 1.28 \\
\hline V8. 'Business ethics' is a concept for public relations only. & 2.10 & 0.96 & 1.99 & 0.78 & 1.75 & 1.01 \\
\hline $\begin{array}{l}\text { V9. The business world today is not different from what it used } \\
\text { to be in the past. Business Ethics has not changed over the past } \\
\text { few years. }\end{array}$ & 2.26 & 1.07 & 1.98 & 1.05 & 1.97 & 1.20 \\
\hline $\begin{array}{l}\text { V10. Competitiveness and profitability are independent values } \\
\text { (existing on their own). }\end{array}$ & 2.52 & 1.12 & 2.26 & 1.01 & 2.20 & 1.20 \\
\hline V11. As a consumer when making a car insurance claim, I try to & 3.11 & 1.19 & 3.31 & 1.40 & 2.71 & 1.46 \\
\hline
\end{tabular}




\begin{tabular}{|c|c|c|c|c|c|c|}
\hline $\begin{array}{l}\text { V12. While shopping at the supermarket it is appropriate to } \\
\text { switch price tags if the opportunity arises. }\end{array}$ & 1.88 & 1.18 & 1.60 & 0.93 & 1.37 & 0.98 \\
\hline $\begin{array}{l}\text { V13. As an employee, I take office supplies home; it doesn't hurt } \\
\text { anyone. }\end{array}$ & 1.81 & 1.02 & 2.15 & 1.83 & 1.57 & 0.85 \\
\hline V14. I view sick days as vacation days that I deserve. & 2.29 & 1.23 & 2.12 & 1.05 & 1.91 & 1.20 \\
\hline $\begin{array}{l}\text { V15. Employee wages should be determined according to the } \\
\text { laws of supply and demand. }\end{array}$ & 2.77 & 1.26 & 2.70 & 1.38 & 2.90 & 1.37 \\
\hline $\begin{array}{l}\text { V16. For every decision in business the only question I ask is, } \\
\text { 'Will it be profitable?'. If yes - I will act according; if not, it is } \\
\text { irrelevant and a waste of time. }\end{array}$ & 3.20 & 1.41 & 2.56 & 1.33 & 2.71 & 1.46 \\
\hline $\begin{array}{l}\text { V17. In my grocery store every week I raise the price of a certain } \\
\text { product and mark it 'on sale'. There is nothing wrong with doing } \\
\text { this. }\end{array}$ & 1.99 & 0.97 & 2.07 & 1.62 & 1.54 & 0.97 \\
\hline V18. The business world has its own rules & 3.27 & 1.08 & 3.44 & 1.14 & 4.11 & 1.04 \\
\hline V19. A good business person is a successful business person. & 3.15 & 1.34 & 3.12 & 1.18 & 3.10 & 1.24 \\
\hline V20. True morality is first and foremost self-interested. & 3.08 & 1.20 & 2.99 & 1.07 & 4.12 & 1.07 \\
\hline V21. Self-sacrifice is immoral. & 2.37 & 1.17 & 2.36 & 0.85 & 1.88 & 1.13 \\
\hline $\begin{array}{l}\text { V22. You can judge a person according to his work and his } \\
\text { dedication. }\end{array}$ & 3.96 & 0.95 & 3.29 & 1.27 & 3.44 & 1.14 \\
\hline V23. You should not consume more than you produce. & 3.90 & 1.12 & 2.98 & 1.32 & 3.88 & 1.20 \\
\hline
\end{tabular}

The comparison of the results for the three sets of data shows that there were areas of similarities and differences in the mean average values. The trend in the results shows similarities between Botswana and South Africa for V1, V4, V11, V17 and V20. V1 shows a higher level of agreement for Botswana and South Africa on that 'a person who is doing well in business does not have to worry about money problems'. This value measures a person's personal attitude and approach to business as a money-making venture, thus the extent to which morality may be allowed to prevail over profitability. This observation is corroborated by the results reported by V4 where the Turkey results were more disagreeable to the notion that 'business decisions involve a realistic economic attitude and not a moral philosophy'. The averages for Botswana and South Africa were more agreeable on business needing to have some levels of moral consciousness over economic aspects of the business.

V11, V12 and V17 all relate to an individual's propensity to make personal gains by 'cheating' other establishments outside their own workplace. For V12 there was no notable difference in the mean value for the three sets of data, although the results for Botswana leaned more towards 'disagree' as opposed to 'strongly disagree' as is the case for South Africa and Turkey. V11 and V17 however suggest that Botswana and South African respondents were more amenable to 'gaming' a system in order to increase personal financial gains from other business entities (in this case insurance companies) and customers.

This group of value systems energized students and led to lengthy discussions on the right and wrong of such actions. One of the issues raised was that as part of the Botswana culture people are encouraged to receive any 'gift' that arise from the error of others since God will not give to you directly, but does so indirectly though other people. Though seemingly agreeing with this notion the following responses suggest that the values in question did not fall within this category. For example, a respondent pointed out that:

First respondent: Increasing an insurance claim in order to get more money is not a 'gift from God', but is a fraudulent act. It is not the same as finding a box full of money on the roadside.

Second respondent: But it is. Both do not belong to you.

First respondent: No, keeping money that you find is a claim on your luck because some other random person will gain from your failure to take the money........ The other thing is that there is no risk of being identified since so many people will pass down the same roadside

\section{Group 2 respondents.}

For the statement labelled V20 which seeks to measure perceptions on whether true morality is first and 
foremost self-interest', the Turkey survey resulted in a mean of 4.12 which lies between the 'agree' and 'strongly agree' responses. This appears to be indicative of a society that has individualistic characteristics. The mean figures for Botswana and South Africa were 3.08 and 2.99 respectively which are close to the 'not sure' response. This would then suggest a more collective society in which the individual are less motivated by self-interest and are more likely to act in the interest of the group. This cultural trait is often espoused by principles of 'botho' or ' $u b u n t u$ ' in the Southern African region.

\subsection{Business Environment and Ethical Consequences}

Having analyzed some of the findings of the study, it is worth discussing some of the elements that came out of the discussion groups which will help understand respondents' perceptions. One of the outcomes of the group discussions that were not included in the ATBEQ is how the environment shapes peoples' perceptions on ethics, and the outcome of unethical conduct. More specifically, respondents' attitudes towards ethical behaviour appeared to be shaped and informed by reports within their environment of ethical misconduct and the resulting outcome of unethical practices. On the main, the discussions revealed that when students heard of unethical practices that had occurred but were ultimately unresolved or accused persons got away without charges, then this would lower their 'ethical resolve'. This was heightened by anxieties of what would happen, for example, to a whistleblower if a company's fraudulent activities are not uncovered. As some respondents offered:

First Respondent: Imagine losing your job as an accountant over something that never sees the light of day! Who is going to employ you after that? People in the company, bad guys, will keep their jobs and you'll be in dark house for a long time.

Second Respondent: So being a bad guy pays? How? The time for thinking about how we will be at work is now, not when you get there.

Third Respondent: I think we are taught [business ethics] now, but we will only know how to apply it when we get to the work-place. Group 2 respondents.

Interestingly, one respondent suggested there are often indications of a gap between ethical decisions and ethics education well before students join the formal work-place. When discussing the relevance of ethics education as offered in their degree program and the impact this is likely to have once they join the job market, a respondent had this to say:

Respondent: (addressing the interviewer).... you have caught some students copying in their business ethics test. If they can do this now when ethics is still hot on their minds, how they apply it when they have left school? Group 3 respondent

This revelation goes beyond the unethical behaviour shown by students when they copy during assessments, or when they engage in similar unacceptable acts. It suggests that business ethics is often taught in colleges and universities without the desired learning on the part of some students.

Another disclosure that emerged during the group discussions is that there is a certain degree of uncertainty in students' minds when it comes to the motives and reasons that drive people towards unethical business conduct. In-fact, this uncertainty about impeding behaviour once they are gainful employment seemed to be an enigma to some students. As one respondent stated:

We pursue business degree so that we can make good money and earn a good living. We want to do it the right way, and we probably will do things right. But you can't judge people now who are involved in all sorts of things till you get there (to the work-place). I think it's better to distance yourself from bad activities of companies once you start working. What we learn about (the) Enrons should be enough of a lesson. Group 1 respondent.

The hesitation shown by students to clearly and unequivocally distance themselves from likely unethical conduct, not least because they have been exposed to some of the consequences of such behaviour through their study of business ethics, is both bewildering and of concern. Notwithstanding this, the implications of these disclosures is that the future ethical conduct is incumbent on the current business environment and the legislature sending clear messages and examples that will deter the 'new breed' of managers and accountants from engaging in activities that are fraught with unethical business practices.

\section{Discussion}

\subsection{Observations Made from the Findings of the Study}

One of the first observations made by the researcher is that business ethics appears to have escaped efforts towards making it universal. Somewhere between notions of cultural influences, issues of legality and religious 
dictates, people appear to have formed their own ideas of what will be 'acceptable' ethical behaviour in a given setting. For example, some of the respondents have already formed the view that they will follow ethical behavioural patterns that they find prevailing in the workplace. Similarly, researchers appear to 'accept' that culture, peoples' histories and the external environment will inform the ethical environment. Does this not lead to some level of ethical complacency? Notwithstanding these concerns, a comparison of the quantitative results indicate that both South African and Botswana, which are mapped as having a fairly strong uncertainty avoidance index by the Hofstede's study (2004) suggesting that students are in-fact likely to follow informal and formal rules that are set in the workplace.

The view presented by respondents who intend to follow the ethical values that they found in the workplace is particularly worrying. Having taken a course in ethics, students have become aware of growing concerns over frequent reports of corruption, fraud and bribery being practiced by some of the leading organizations in the country. Graduates who get caught between endeavouring for personal financial survival and ethical conduct are more open to poor ethical judgement when they are in gainful employment. As one respondent put it, the time for business students to make ethical choices 'is now'. Thus college and public education, as well as government policy can be useful in driving ethical reform and setting the standards for expected ethical conduct (see also Abdolmohammadi et al., 2003).

Given some of the comments made by some focus groups respondents, there, at times, appeared to be two levels of ethics in play; one that is desired or scripted to depict intended good behaviour, and one of a lower level that will be evoked when lucrative business opportunities arise. This observation was made following the qualitative part of the study which revealed some of the more callous viewpoints held by young respondents.

The findings of the study also point some differences in perception about ethical behaviour by gender. Although the analysis of the quantitative results intimated that there are subtle differences in conceptual and moral value items, the interview responses suggest that there is significant difference between males and females in terms of ethical behaviour and perceptions in some ethical issues. In the qualitative part of the study some female respondents stated that their male counterparts are more daring and willing to the point of engaging in unethical behaviour.

Finally, the study determined that a good number of students agreed that religion teaches some ethical values, a sentiment shared by some studies. For example, Conroy and Emerson (2004) suggest that religious people are less willing to act unethically, but that this relationship has not been fully explored. To this end the researchers go on to suggest that pedagogical methods that focus on community service learning, on-site visits to corporations and specific organized process of instruction can alter ethical attitudes. Koys (2001) makes a more radical suggestion when he posits that religious tradition should be incorporated into business ethics curricula.

\section{Conclusions}

One of the greatest benefits of conducting the current study was the opportunity to assess and gain feedback from students on their perceptions and views on business ethics. It is not clear whether courses in ethics and auditing have shaped ethical views in any way, but taking an 'inventory' of perceptions will be useful in shaping the curriculum and gaining insight on the likely ethical conduct of future accountants and managers.

There were however a few limitations that are note-worthy. Some relate to the study, while others are embedded in the ATBEQ.

\section{Limitations of the Study}

The main limitation of the study was the pool of available respondents that the study could draw on. Since the ethics course had only been introduced in the previous year, making the respondents to this study is only beneficiaries, a longitudinal study could not be conducted. In future, and with work experience, a repeat study could advance our understanding of the phenomenon.

Another limitation of the study was the age and experience of respondents. As Peterson et al., (2001) contend, younger business professionals tend to exhibit lower ethical belief than their older counterparts. Though informative in revealing students perceptions, a mature and professionally experienced group of respondent could have provided useful comparisons.

\subsection{Limitations of the ATBEQ Instrument}

The current study adds to a growing plethora of studies that intend to determine attitudes towards business ethic in different settings, as well as uncovering factors that inform or influence such behaviour patterns. Culture appears to be an important factor in explaining these patterns, but clear associations between ethical views and 
conducts and cultural traits are yet to be made. More specifically, the ATBEQ instrument has several limitations that prevent it from enabling researchers to begin to uncover the specific links between ethics, culture, and other theoretical viewpoints. The main setback in its use is that researchers have not actively sought to triangulate their findings with qualitative data that could advance our understanding of these attitudes. Qualitative data could also provide feedback on the usefulness of the instrument and the questions included therein. It is the continuous use of the instrument in its original 30-value question format that has led some researchers to call for its review (Moore \& Radloff, 1996). The current study certainly supports this appeal.

\section{References}

Abdolmohammadi, M. J., Read, W. J., \& Scarbrough, D. P. (2003). Does Selection-Socialisation help to explain Accountants' Weak Ethical Reasoning? Journal of Business Ethics, 42, 71-81. http://dx.doi.org/10.1023/A:1021691001119

Ahmed, M., Chung, K., \& Eichenseher, J. (2003). Business Students' Perception of Ethics and Moral Judgement: A Cross-Cultural Study. Journal of Business Ethics, 43, 89-102. http://dx.doi.org/10.1023/A:1022915316112

Bean, D. F., \& Bernardi, R. A. (2007). Ethics education in our colleges and universities: A positive role for accounting practitioners. Journal of Academic Ethics, 5, 59-75. http://dx.doi.org/10.1007/s10805-007-9038-4

Bernardi, R. A., \& Bean, D. F. (2006). Ethics in accounting education: The forgotten stakeholders. The CPA Journal, 1-5.

Conroy, S., \& Emerson, T. (2004). Business Ethics and Religion: Religiosity as a Predictor of Ethical Awareness amongst students. Journal of Business Ethics, 50, 383-396. http://dx.doi.org/10.1023/B:BUSI.0000025040.41263.09

Deng, F. M. (1997). Ethnicity: An African Predicament. Brookings Review, 15(3), 28-31. http://dx.doi.org/10.2307/20080749

Emerson, T. L. N., \& McKinney, J. A. (2010). Importance of Religious Belief to Ethical Attitudes in Business. Journal of Religious and Business Ethics, 1(2).

Fatoki, O., \& Marembo, M. (2012). An investigation into the Attitudes towards Business Ethics by University Students in South Africa. African Journal of Business Management, 6(18), 5865-5871.

Gichure, C. (2006). Teaching Business Ethics in Africa: What Ethical orientation? The Case of East and Central Africa. Journal of Business Ethics, 63, 39-52. http://dx.doi.org/10.1007/s10551-005-1129-9

Gundersen, E., Capozolli, E. A., \& Rajamma, R. K. (2008). Learned ethical behaviour: An academic perspective. Journal of Education for Business, 315-323. http://dx.doi.org/10.3200/JOEB.83.6.315-324

Harvey, B. (1999). Graceful Merchants: A Contemporary View of Chinese Business Ethics. Journal of Business Ethics, 20(1), 85-88. http://dx.doi.org/10.1023/A:1005795117923

Kim, D., Fisher, D., \& McCalman, D. (2009). Modernism, Christianity and Business Ethics: A Worldview Perspective. Journal of Business Ethics, 90(1), 115-121. http://dx.doi.org/10.1007/s10551-009-0031-2

Hofstede, G. (2004). Cultural Consequences; Comparing Values, Behaviour, Institutions and Organizations Across Nations (2nd ed.). Sage Publications.

Koys, D. J. (2001). Integrating Religious Principles and Human Resources Management. Teaching Business Ethics, 5, 141-156. http://dx.doi.org/10.1023/A:1011490913223

Kruger, T., \& Roodt, G. (2003). Hofstede's VSM-94 revisited: Is it Reliable and valid? SA Journal of Industrial Psychology, 29(1), 75-82. http://dx.doi.org/10.4102/sajip.v29i1.85

Lim, C., \& Lay, C. S. (2003). Confucianism and the Protestant Work Ethics. Asia Europe Journal, 1, 321-322. http://dx.doi.org/10.1007/s10308-003-0038-8

Macfarlane, B. (1995). Business Ethics: too little, too late. Education and Training, 37(5), 32-37. http://dx.doi.org/10.1108/00400919510089130

Macfarlane, B. (1998). Business Ethics and the Idea of Higher Education. Teaching Business Ethics, 2(1), 35-42. http://dx.doi.org/10.1023/A:1009757402637

Mangaliso, M. P. (1997). South Africa; Corporate Social Responsibility and the Sullivan Principle. Journal of Black Studies, 28(2), 219-238. 
Maree, K. W., \& Radloff, S. (2007). Factors affecting Ethical Judgement of South African Chartered Accountants. Meditari Accountancy Research, 15(1), 1-18. http://dx.doi.org/10.1108/10222529200700001

Mbigi, L., \& Maree J. (1995). Ubuntu: The Spirit of African Transformation Management. Randburg, Knowledge Resources.

McSweeney, B. (2002). Hofstede's Model of National Cultural Differences and their Consequences: A Triumph of Faith-a Failure of Analysis. Human Relations, 55(1), 89-118.

Milanzi, M. C. (1997). Business Ethics in Eastern and Southern Africa. Journal of Business Ethics, 16(14), 1549-1553. http://dx.doi.org/10.1023/A:1005811014294

Moore, R., \& Radloff, S. (1996). Attitudes towards Business Ethics held by South African Students. Journal of Business Ethics, 15(8), 863-869. http://dx.doi.org/10.1007/BF00381854

Palumba, F. A., \& Teich, M. (2004). Market Segmentation Based on level of Acculturation. Marketing Intelligence \& Planning, 22(4), 472-484. http://dx.doi.org/10.1108/02634500410542761

Peterson, D., Rhoads, A., \& Vaught, B. (2001). Ethical Beliefs of Business Professionals: A Study of Gender, Age and External Factors. Journal of Business Ethics, 31(3), 225-232. http://dx.doi.org/10.1023/A:1010744927551

Perryer, C., \& Jordon, C. (2002). The Influence of Gender, Age, Culture and Other Factors on Ethical Belief: A Comparative Study in Australia and Singapore. Public Administration \& Management: An Interactive Journal, 7(4), 367-382.

Phau, I., \& Kea, G. (2007). Attitudes of University Students Business Ethics: A Cross-National Investigation of Australia, Singapore and Hong Kong. Journal of Business Ethics, 72(1), 61-75. http://dx.doi.org/10.1007/s10551-006-9156-8

Prebel, J. F., \& Reichel, A. (1988). Attitudes towards Business Ethics of Future managers in the U.S. and Israel. Journal of Business Ethics, 7, 941-949.

Rice, G. (1999). Islamic Ethics and the Implications for Business. Journal of Business Ethics, 18(4), 345-358. http://dx.doi.org/10.1023/A:1005711414306

Rokham, W. (2010). The Effects of Islamic Work Ethics on Work Outcomes. Electronic Journal of Business Ethics and Organizational Studies (EJBO), 15(1), 21-27.

Rossouw, G. J. (1997). Business Ethics in South Africa. Journal of Business Ethics, 16(14), 1539-1547. http://dx.doi.org/10.1023/A:1005858930223

Scholtens, L. J., \& Dam, L. (2007). Cultural Values and International Differences in Business Ethics. Journal of Business Ethics, 75, 273-284. http://dx.doi.org/10.1007/s10551-006-9252-9

Sims, R., \& Gegez, A. (2004). Attitudes Towards Business Ethics: A Five Nation Comparative Study. Journal of Business Ethics, 50(14), 253-265. http://dx.doi.org/10.1023/B:BUSI.0000024708.07201.2d

Sims, R. R. (2002). Business Ethics Teaching for Effective Learning. Teaching Business Ethics, 6(4), 393-410. http://dx.doi.org/10.1023/A:1021107728568

Thomas, A., \& Bendixen, M. (2000). The Management Implications of Ethnicity in South Africa. Journal of International Business Studies, 31(3), 507-519. http://dx.doi.org/10.1023/B:BUSI.0000024708.07201.2d

Turner, J. H. (1997). The Institutional Order. New York: Addison-Wesley Educational Publishers.

Weaver, G. R., \& Agle, B. R. (2002). Religiosity and Ethical Behaviour in Organizations: A Symbolic Interactionist' Perspective. Academy of Management Review, 27(1), 77-97.

Weber, J. (1990). Measuring the Impact of Teaching Ethics to Future Managers: A Review, Assessment and Recommendations. Journal of Business Ethics, 9, 183-190. http://dx.doi.org/10.1007/BF00382643

Wennekers, S., Thurik, R., Van Stel, A., \& Noorderhaven, N. (2007). Uncertainty Avoidance and the rate of Business Ownership across 21 OECD Counties, 1976-2004. Journal of Evolutionary Economics, 17(2), 133-160. http://dx.doi.org/10.1007/s00191-006-0045-1 


\section{Copyrights}

Copyright for this article is retained by the author(s), with first publication rights granted to the journal.

This is an open-access article distributed under the terms and conditions of the Creative Commons Attribution license (http://creativecommons.org/licenses/by/3.0/). 